\title{
Part the first, 2020 reflected: individuals
}

\author{
Stephen Hancocks OBE \\ Editor-in-Chief
}

The BDJ Upfront section includes editorials, letters, news, book reviews and interviews. Please direct your correspondence to the News Editor,

Kate Quinlan atk.quinlan@nature.com. Press releases or articles may be edited, and should include a colour photograph if possible.

$\mathrm{T}$ he $B D J$ is published 24 times in a calendar year with cover dates on the second and fourth Fridays of each month. This means that there are two issues for every month but that sometimes, because there are 52 weeks in the year and because of the way that the dates fall, there is a 'three-week gap'. The other variation to this tightly regulated scheme is that in December, because of the Christmas holidays, the journal is published on the second and third Fridays. Therefore, at this point readers receive three copies in four weeks meaning a hectic editorial and production schedule.

I recount all this to explain my editorial plan for this and the next two issues, in which I intend to reflect on our extraordinary year and, in sequence, the effect that the pandemic has had on us as individuals, on dentistry as a whole and on publishing the BDJ Portfolio. I also draw attention to the effect of time as this is central to our understanding of the thinking processes that we have experienced through the pandemic. Many of us will have expressed the view that 2020 has been a very bad year yet I suspect that in due course, don't ask me when, we will look back and question how bad it actually was. Did we really all stay at home for over a month? Our memories are short. In how much detail can you recall the contemporaneous consequences of the 2008/9 economic crisis?

At the time of writing the preliminary results of coronavirus vaccines have been announced bringing an outpouring of delighted optimism. By the time you read this it might all have turned sour again, or there may be multiple vaccines available. Uncertainty has dogged us these past months and is no stranger. But. A big but and loaded with caveats and procedural problems and logistical challenges, but if an effective vaccine does surface then by the middle of 2021 the world could be a better place once again.
However, despite this, an apparently profound view is that life will never be the same again. Yes and no. Yes, for a while we will remember, for a while we will be grateful again for live performances, strive to implement greater prevention, grander public health strategies and philanthropic social schemes. No, soon we will slide back and forget.

Regular readers will know that I am at heart a cheerful optimist and so these cynical doubts belie my belief that beneficial effects will accrue from this dreadful pandemic. My prediction is that ultimately the majority of good will come not through system change but through individual reflection and in dentistry that this will be manifest at all levels and through all team members. of folk previously regarded as 'mere dentists'. A greater compassion and wider world view, especially in healthcare will inevitably follow. For dental care professionals the entwinement of working lives and home lives has been awkward. Working from home using teledentistry for triage; worrying that returning to the surgery risked bringing the virus back to threaten loved ones; distress that dental laboratories may cease to exist. In future there will be greater understanding.

For dentists the worries have been all but overwhelming. The multiple pressures of attempting to provide patient care, business management and financial stabilisation have combined to generate the perfect storm. The fallout from these challenges will

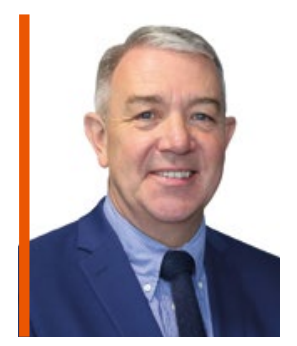

\section{'The majority of good will come not through system change but through individual reflection'}

Students have been having a bad time. While it has been grim enough for those of us with a semblance of stability and established security, for those starting out in their careers it has been an eye-watering view of an horizon mediated by online teaching and blurred by uncertainty. Our enviable human ingenuity has yet been busy devising new ways of conducting exams, managing patient interactions and organising community care. Our clinicians and researchers of tomorrow will have a clearer sense of proportion.

For foundation dentists the shock of redeployment has morphed in many cases into an appreciation of the benefits of greater co-operation, realisation of the portability of their skills into different sectors and the creation of awareness in others of the value reverberate for months and years to come but the immediate aftermath will be marked, I am sure, by schisms in mental and physical health in many of our colleagues. In due course we will establish a more equitable form of dental practice.

This is all focussed internally but patients are the key individuals in our equation. We are all patients at some time and so can personally relate to fears of what to do when in pain, how we can change our behaviour to prevent illness and whether our health and wellbeing will be sufficiently robust to get us through to the other side of the pandemic in one piece. If we thought 2020 vision meant optimal sight perhaps 2021 vision might, curiously, be clearer still. We'll see.

https://doi.org/ 10.1038/s41415-020-2432-7 